\title{
Optimization of sulfuric acid treatment of peanut shells for cellulose contents through Box-Behnken design
}

\author{
SIDRA KANWAL, MUHAMMAD IRFAN * \\ Department of Biotechnology, University of Sargodha, Sargodha, Pakistan
}

\begin{abstract}
Pretreating plant biomasses is an important step for effective lignin removal and degradation of cellulose to fermentable sugars. In this study, we optimized pretreatment conditions for peanut shells (Arachis hypogeae) to obtain the maximum yield of cellulose. For optimization, three parameters were used, i.e., sulfuric acid concentration $(0.6 \%, 0.8 \%$, and $1.0 \%)$, substrate loading $(5 \%, 10 \%$, and $15 \%)$, and residence time $(4 \mathrm{~h}, 6 \mathrm{~h}$, and $8 \mathrm{~h})$ with and without steam $\left(121^{\circ} \mathrm{C}, 15 \mathrm{psi}, 15 \mathrm{~min}\right)$, based on Box-Behnken design of response surface methodology. The results confirmed that the maximum yield of cellulose (71.68\%) was obtained under pretreatment conditions of $1 \%$ sulfuric acid, $15 \%$ substrate loading, and $6 \mathrm{~h}$ residence time. The ANOVA results indicated that the proposed model was highly significant having $F$-value and $P$-value of 158.63 and 0.000 , respectively. Moreover, the efficiency of this pretreatment method was further analyzed using FTIR spectroscopy, indicating structural conformation in the pretreated biomass. The results indicate that the pretreated biomass can be utilized for further processes such as saccharification of lignocellulosic material for bioethanol production.
\end{abstract}

Key words: $\mathrm{H}_{2} \mathrm{SO}_{4}$ pretreatment, peanut shells, FTIR, RSM

\section{Introduction}

Burning fossil fuels such as petroleum, coal, and natural gas, which contain a high percentage of carbon, leads to the emission of $\mathrm{CO}_{2}$, one of the most important greenhouse gases (GHGs). The usage of fossil fuels to fulfill energy requirements is threatened by the rise in the concentration of GHGs in the environment, which has also increased concern over global warming (Demirbas et al., 2004). Thus, a reduction in the consumption of fossil fuels can decrease $\mathrm{CO}_{2}$ emission and the risk of environmental pollution (Demirbas, 2006); however, to fulfill this demand, additional research on the development of renewable energy resources is necessary. Recently, liquid fuels have received considerable interest from researchers as they are expected to replace fossil fuels (Yat et al., 2008).

Bioethanol, or ethyl alcohol $\left(\mathrm{CH}_{3}-\mathrm{CH}_{2}-\mathrm{OH}\right)$, is a volatile, flammable, and colorless liquid (Ruangmee and Sangwichien, 2013), which was used as fuel for the first time in 1987 in an internal combustion engine developed by Nikolas Otto (Rothman et al., 1983). Bioethanol is a good fuel for dedicated engines because of its high octane number, high flame speed, and high heat of vaporization. Similarly, lignocellulosic biomass has been proven as a successful alternative source for producing chemicals and fuel (ethanol) because of its renewable nature (Binder et al., 2009).

Various lignocellulosic biomasses have been exploited for producing bioethanol; however, because of the complex structure of the plant cell wall and its components, it is difficult to breakdown cellulose into a lignocellulosic biomass. Moreover, such cellulose is resistant to many physiochemical, compositional, and structural factors (Hsu et al., 1980). Therefore, cellulose needs to be pretreated before it can be used as a source of biomaterials so that lignin is removed and the compound is made less crystalline, but without any change in its structure. Such a pretreatment process is performed either via

\footnotetext{
* Corresponding author: Department of Biotechnology, University of Sargodha, Sargodha 40100, Pakistan; e-mail: irfan.ashraf@uos.edu.pk; irfan.biotechnologist@gmail.com
} 
a physical process, chemical process, or a combined process. For chemical pretreatment, different acids, bases, and solvents have been used to expose cellulose, which indirectly also helps in the hydrolysis of cellulose and hemicellulose (Vancov et al., 2012). In this study, we have focused on identifying the optimal pretreatment conditions to obtain the maximum yield of cellulose from peanut shells (PS).

\section{Materials and methods}

\section{Substrate collection}

Arachis hpogea (peanut) was collected from Sargodha, Pakistan.

\section{Preparation of substrate (peanut shells)}

The samples (PS) were washed with water to remove dust and dirt. They were then cut into small pieces and the sun-dried substrate was placed in an oven $\left(70^{\circ} \mathrm{C}\right)$ till a consistent weight was achieved. Then, the oven-dried substrate was ground into a fine powder $(2 \mathrm{~mm})$ using a grinding mill.

\section{Pretreatment of peanut shells}

The PS were pretreated with sulfuric acid and sulfuric acid-steam based on the pretreatment methodology of Arshad et al. (2017).

\section{Cellulose estimation}

After pretreatment, the cellulose content was measured using Gopal and Ranjhan (1980)'s method. Acetic acid $(80 \% ; 15 \mathrm{ml})$ and concentrated $\mathrm{HNO}_{3}(1.5 \mathrm{ml})$ were added to the substrate $\left(1 \mathrm{~g}, \mathrm{~W}_{1}\right)$ and digested for $25 \mathrm{~min}$. After refluxing, the material was filtered through Whatman filter paper \#1, and the samples were washed with warm water and transferred into a crucible and ovendried overnight at $105^{\circ} \mathrm{C}$ and weighed $\left(\mathrm{W}_{2}\right)$. Then, the samples were subjected to charring and placed in a muffle furnace at $550^{\circ} \mathrm{C}$ for $5 \mathrm{~h}$ to turn them to ash. Then, the samples were weighed again $\left(\mathrm{W}_{3}\right)$ and the cellulose content was measured using the following formula:

$$
\text { Cellulose [\%] }=\frac{\mathrm{W}_{2}-\mathrm{W}_{3}}{\mathrm{~W}_{1}} \times 100
$$

$\mathrm{W}_{1}$ - weight of material on dry basis; $\mathrm{W}_{2}$ - weight of digested material; $\mathrm{W}_{3}$ - weight of ash

\section{Fourier Transform Infrared Spectroscopy (FTIR) analysis}

FTIR spectra of PS biomass treated with sulfuric acid were obtained to verify the changes in the structural arrangement of cellulose. For obtaining the FTIR spectra, both the untreated PS and pretreated solid residues from the acid $\left(\mathrm{H}_{2} \mathrm{SO}_{4}\right)$ pretreatment were analyzed using the Agilent technology Cary 630 spectrometer. The spectrum obtained was magnified between 500 and $4000 \mathrm{~cm}^{-1}$.

\section{Experimental design}

A three-variable Box-Behnken design of response surface methodology (RSM) was used to study the combined effect of the above variables on the cellulose content in PS after pretreatment. The Box-Behnken design is appropriate for examining quadratic response surfaces and creates a second-degree polynomial model, which is used for improving the process using a small number of experimental runs. We performed randomized 13 experimental runs to exploit the effects of unsolved variability in the observed responses because of extraneous factors. The relation between the coded values and actual values is described in Equation (Eq. 1):

$$
x_{i}=\frac{X_{i}-X_{o}}{\Delta X_{i}}
$$

where $X_{i}$ and $X_{i}$ are the coded and actual values of the independent variable, respectively; $X_{o}$ is the actual value of the independent variable at the center point; and $\Delta X_{i}$ is the step change of $X_{i}$ (Jabasingh and Nachiyar, 2011). To estimate the response of the dependent variable and predict the optimal point, a second-degree polynomial model is fitted to the experimental data using the statistical package software Minitab v. 17.0. The second-degree polynomial model is expressed as Equation (eq. 2):

$$
Y=\beta_{0}+\Sigma_{i=l}^{k} \beta_{i x_{i}}+\sum_{i=l}^{k} \beta_{i i x_{i}^{2}}+\sum_{i<j}^{k} \Sigma_{j}^{k} \beta_{i j} x_{i} x_{j} \quad \text { Eq. } 2
$$

where $Y$ is the response of cellulose contents; $\beta_{0}$ is the constant coefficient; $\beta_{i}, \beta_{i j}$, and $\beta_{i j}$ are coefficients for the linear, quadratic, and interaction effects, respectively; and $X_{i}$ is the independent variable factor, representing either the $\mathrm{H}_{2} \mathrm{SO}_{4}$ concentration $(\mathrm{g} / \mathrm{l})$, the temperature $\left({ }^{\circ} \mathrm{C}\right)$, or the reaction time (min). 
Table 1. Coded and actual levels of three factors used in Box-Behnken design (BBD) for acid and acid steam pretreatment

\begin{tabular}{l|c|c|c|c}
\hline \multirow{2}{*}{ Independent variable } & \multirow{2}{*}{ Code } & \multicolumn{3}{|c}{ Code and actual factor level } \\
\cline { 3 - 5 } & & -1 & 0 & +1 \\
\hline $\mathrm{H}_{2} \mathrm{SO}_{4}$ concentration $[\% \mathrm{w} / \mathrm{v}]$ & $x_{1}$ & 0.6 & 0.8 & 1.0 \\
\hline Substrate concentration $[\mathrm{g}]$ & $x_{2}$ & 5 & 10 & 15 \\
\hline Reaction time $[\mathrm{h}]$ & $x_{3}$ & 4 & 6 & 8 \\
\hline
\end{tabular}

Table 2. Experimental design showing the observed and predicted values of variables and cellulose percentage in samples pretreated with dilute sulfuric acid

\begin{tabular}{c|c|c|c|c|c|c}
\hline \multirow{2}{*}{$\begin{array}{c}\text { Run } \\
\text { number }\end{array}$} & $X_{1}$ & $X_{2}$ & $X_{3}$ & \multicolumn{2}{|c|}{ Cellulose [\%] } & \multirow{2}{*}{ Residual value } \\
\cline { 5 - 6 } & & & & Observed & Predicted & \\
\hline 1 & 0.8 & 10 & 6 & 42.20000 & 42.20000 & -0.000000 \\
\hline 2 & 1.0 & 10 & 8 & 48.60000 & 48.31000 & 0.290000 \\
\hline 3 & 1.0 & 15 & 6 & 71.68000 & 71.16000 & 0.520000 \\
\hline 4 & 1.0 & 10 & 4 & 48.00000 & 48.01000 & -0.010000 \\
\hline 5 & 1.0 & 5 & 6 & 47.00000 & 47.80000 & -0.800000 \\
\hline 6 & 0.6 & 15 & 6 & 44.40000 & 43.60000 & 0.800000 \\
\hline 7 & 0.8 & 5 & 4 & 41.40000 & 40.59000 & 0.810000 \\
\hline 8 & 0.6 & 10 & 8 & 37.20000 & 37.19000 & 0.010000 \\
\hline 9 & 0.8 & 15 & 8 & 45.40000 & 46.21000 & -0.810000 \\
\hline 10 & 0.6 & 10 & 4 & 38.20000 & 38.49000 & -0.290000 \\
\hline 11 & 0.6 & 5 & 6 & 54.20000 & 54.72000 & -0.520000 \\
\hline 12 & 0.8 & 5 & 8 & 36.40000 & 35.89000 & 0.510000 \\
\hline 13 & 0.8 & 15 & 4 & 42.00000 & 42.51000 & -0.510000 \\
\hline
\end{tabular}

Table 3. Experimental designs showing the observed and predicted values of variables and cellulose percentage in samples pretreated with dilute sulfuric acid-steam

\begin{tabular}{c|c|c|c|c|c|c}
\hline \multirow{2}{*}{$\begin{array}{c}\text { Run } \\
\text { number }\end{array}$} & \multirow{2}{*}{$X_{1}$} & $X_{2}$ & $X_{3}$ & \multicolumn{2}{|c|}{ Cellulose [\%] } & \multirow{2}{*}{ Residual value } \\
\cline { 5 - 6 } & & & & Observed & Predicted & \\
\hline 1 & 0.8 & 10 & 6 & 41.20000 & 41.20000 & -0.000000 \\
\hline 2 & 1 & 10 & 8 & 44.00000 & 43.80250 & 0.197500 \\
\hline 3 & 1 & 15 & 6 & 63.02000 & 62.46500 & 0.555000 \\
\hline 4 & 1 & 10 & 4 & 48.20000 & 48.80250 & -0.602500 \\
\hline 5 & 1 & 5 & 6 & 38.60000 & 38.75000 & -0.150000 \\
\hline 6 & 0.6 & 15 & 6 & 41.60000 & 41.45000 & 0.150000 \\
\hline 7 & 0.8 & 5 & 4 & 40.40000 & 39.64750 & 0.752500 \\
\hline 8 & 0.6 & 10 & 8 & 49.60000 & 48.99750 & 0.602500 \\
\hline 9 & 0.8 & 15 & 8 & 53.00000 & 53.75250 & -0.752500 \\
\hline 10 & 0.6 & 10 & 4 & 32.20000 & 32.39750 & -0.197500 \\
\hline 11 & 0.6 & 5 & 6 & 48.00000 & 48.55500 & -0.555000 \\
\hline 12 & 0.8 & 5 & 8 & 39.20000 & 39.24750 & -0.047500 \\
\hline 13 & 0.8 & 15 & 4 & 41.80000 & 41.75250 & 0.047500 \\
\hline
\end{tabular}


Table 4. Analysis of variance for the regression equations of cellulose yield for dilute sulfuric acid pretreatment

\begin{tabular}{l|c|c|c|c|c}
\hline \multicolumn{1}{c|}{ Source } & DF & Adj SS & Adj MS & $F$-value & $P$-value \\
\hline Model & 9 & 742.987 & 82.554 & 158.63 & 0.000 \\
\hline Linear & 3 & 268.058 & 89.353 & 171.69 & 0.000 \\
\hline $\mathrm{H}_{2} \mathrm{SO}_{4}$ conc. $x_{1}$ & 1 & 62.832 & 62.832 & 120.73 & 0.000 \\
\hline Substrate conc. $x_{2}$ & 1 & 137.946 & 137.946 & 265.07 & 0.000 \\
\hline Time $x_{3}$ & 1 & 67.280 & 67.280 & 129.28 & 0.000 \\
\hline Square & 3 & 82.381 & 27.460 & 52.77 & 0.000 \\
\hline$x_{1}^{2}$ & 1 & 39.060 & 39.060 & 75.05 & 0.000 \\
\hline$x_{2}^{2}$ & 1 & 41.499 & 41.499 & 79.74 & 0.000 \\
\hline$x_{3}^{2}$ & 1 & 3.350 & 3.350 & 6.44 & 0.052 \\
\hline 2 -Way interaction & 3 & 392.548 & 130.849 & 251.43 & 0.000 \\
\hline$x_{1} x_{2}$ & 1 & 237.468 & 237.468 & 456.30 & 0.000 \\
\hline$x_{1} x_{3}$ & 1 & 116.640 & 116.640 & 224.13 & 0.000 \\
\hline$x_{2} x_{3}$ & 1 & 38.440 & 38.440 & 73.86 & 0.000 \\
\hline Error & 5 & 2.602 & 0.520 & & \\
\hline Lack-of-fit & 3 & 2.602 & 0.867 & & \\
\hline Pure error & 2 & 0.00 & 0.00 & & \\
\hline Total & 14 & & 745.589 & & \\
\hline
\end{tabular}

Table 5. Analysis of variance for the regression equations of cellulose yield for dilute sulfuric acid-steam pretreatment

\begin{tabular}{l|c|c|c|c|c}
\hline \multicolumn{1}{c|}{ Source } & DF & Adj SS & Adj MS & $F$-value & $P$-value \\
\hline Model & 9 & 1043.18 & 115.908 & 151.65 & 0.000 \\
\hline Linear & 3 & 288.41 & 96.138 & 125.78 & 0.000 \\
\hline $\mathrm{H}_{2} \mathrm{SO}_{4}$ conc. $x_{1}$ & 1 & 213.00 & 213.005 & 278.69 & 0.000 \\
\hline Substrate conc. $x_{2}$ & 1 & 74.91 & 74.909 & 98.01 & 0.000 \\
\hline Time $x_{3}$ & 1 & 0.50 & 0.500 & 0.65 & 0.455 \\
\hline Square & 3 & 439.27 & 146.422 & 191.57 & 0.000 \\
\hline$x_{1}^{2}$ & 1 & 176.30 & 176.301 & 230.66 & 0.000 \\
\hline$x_{2}^{2}$ & 1 & 100.22 & 100.224 & 131.13 & 0.000 \\
\hline$x_{3}^{2}$ & 1 & 137.84 & 137.842 & 180.35 & 0.052 \\
\hline 2 -Way interaction & 3 & 315.50 & 105.166 & 137.59 & 0.000 \\
\hline$x_{1} x_{2}$ & 1 & 297.22 & 297.218 & 388.87 & 0.000 \\
\hline$x_{1} x_{3}$ & 1 & 0.64 & 0.640 & 0.84 & 0.402 \\
\hline$x_{2} x_{3}$ & 1 & 17.640 & 17.640 & 23.08 & 0.005 \\
\hline Error & 5 & 3.82 & 0.764 & & \\
\hline Lack-of-fit & 3 & 3.82 & 1.274 & & \\
\hline Pure error & 2 & 0.00 & 0.00 & & \\
\hline Total & 14 & & 1047.00 & & \\
\hline & & & & &
\end{tabular}




\section{Statistical analysis}

Minitab v. 17.0 Trial Version was used for plotting graphs and for the regression analysis. The ANOVA $F$-test was used for verifying the model's significance.

\section{Results and discussion}

Recently, a lot of researchers are focusing on biofuel production from lignocellulosic biomass, which is a renewable energy source (Binder et al., 2009). The pretreatment of lignocellulosic biomass is a very important step to remove hemicellulose and lignin by disturbing their structure and to improve enzymatic hydrolysis (Alvira et al., 2010). This process enhances the enzymatic conversion of cellulose to sugar units (Satyanagalakshmi et al., 2011) and reduces the need for digestion using hemicellulases (Saha, 2004). For improving the enzymatic hydrolysis of cellulose, pretreatment with dilute sulfuric acid and acetic acid was used in a number of studies (Satyanagalakshmi et al., 2011). Gajula et al. (2011) used groundnut shells for conversion to fermentable sugars with sodium sulfite being used for delignification. After enzymatic hydrolysis with commercial cellulase $\left(50 \mathrm{~h}, 120 \mathrm{rpm}, 50^{\circ} \mathrm{C}\right)$, the yield obtained was $670 \mathrm{mg} / \mathrm{g}$.

In this study, PS were pretreated using dilute acid to increase the accessibility of cellulose. Chemically, PS are composed of $40 \%$ cellulose, $26 \%$ lignin, and $14.7 \%$ hemicelluloses; therefore, they have a good amount of sugars that can be converted to biofuel (Van Dyk et al., 2012). Unfortunately, because of the high lignin content, PS require pretreatment. For this purpose, three parameters, i.e., the amount of substrate $(5,10$, and $15 \%)$, sulfuric acid concentration $(0.6,0.8$, and $1 \%)$, and pretreatment time $(4 \mathrm{~h}, 6 \mathrm{~h}, 8 \mathrm{~h})$ were studied. In this study, we determined that the raw PS contained 32.4\% cellulose. Kiran and coworkers (2013) reported similar results with 33\% cellulose content in acid-treated PS. The percentage of cellulose content in samples pretreated with dilute $\mathrm{H}_{2} \mathrm{SO}_{4}$ improved significantly (from 36.4 to $71.6 \%$ ) (Table 2), while in acid-steam pretreated samples, the percentage ranged from 32.2 to $63.02 \%$ (Table 3). Note that sulfuric acid concentration of $1 \%$, substrate loading of $15 \%$, and $6 \mathrm{~h}$ of residence time resulted in the maximum yield of 71.6 and $63.02 \%$ of cellulose in pretreated sulfuric acid and sulfuric acid-steam pretreated PS samples, respectively. All responses toward both treatments were calculated via second order polynomial regression equations, as shown in Eq. 3 and Eq. 4.

The regression equation for cellulose content for dilute $\mathrm{H}_{2} \mathrm{SO}_{4}$ pretreated samples is as follows:

$$
\begin{aligned}
\text { Cellulose }[\%] & =179.0-342.8 X_{1}-11.712 X_{2}+15.31 X_{3}+ \\
& +172.8+0.2084-1.528+8.620 X_{1} X_{2}+ \\
& +1.00 X_{1} X_{3}+0.2100 X_{2} X_{3}
\end{aligned}
$$

The regression equation for cellulose content of dilute $\mathrm{H}_{2} \mathrm{SO}_{4}$-steam pretreated samples is as follows:
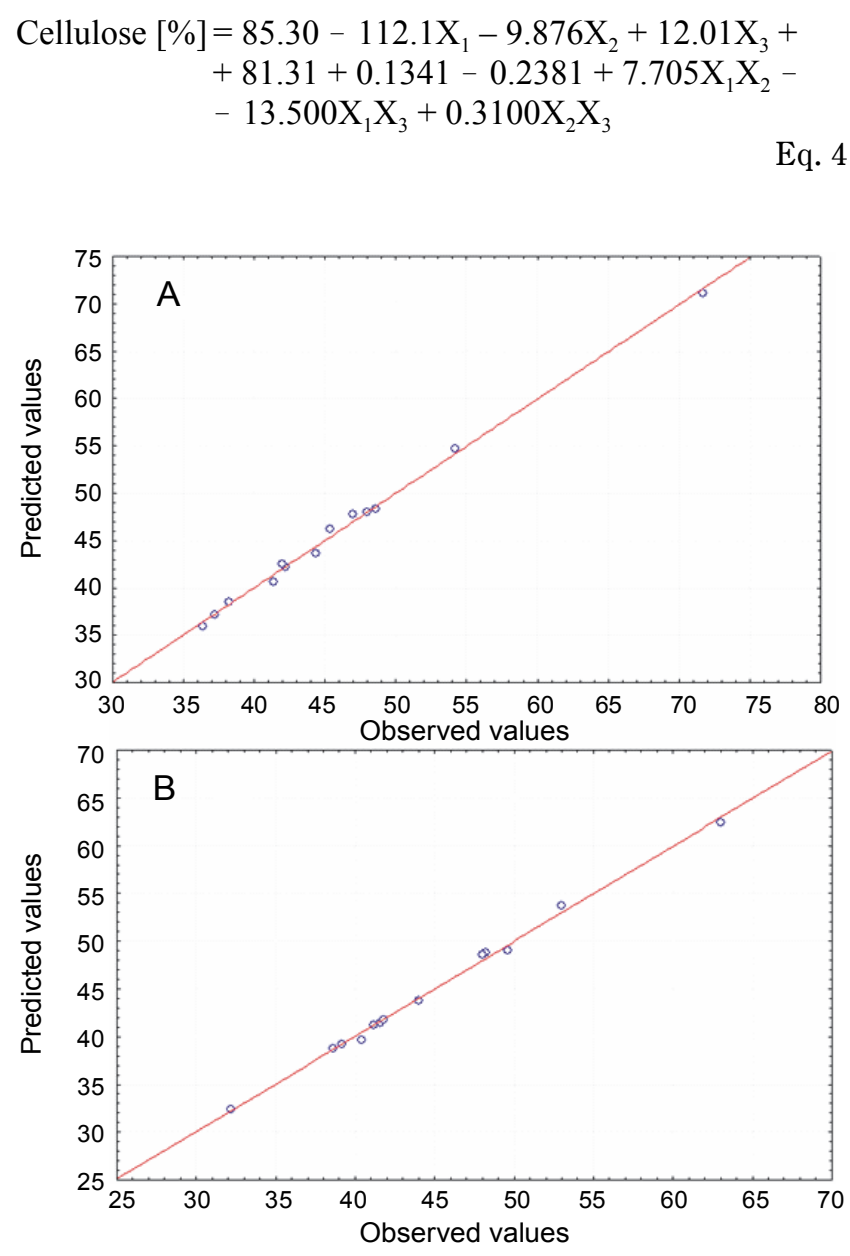

Fig. 1. Correlation between the observed versus A) the predicted values of cellulosic content of acid treated and B) acid-steam pretreated peanut shell samples

Tables 4 and Table 5 show the analysis of variance of cellulose yield for dilute sulfuric acid and dilute sulfuric acid-steam pretreatments. The large $F$-values of 158.63 (dilute sulfuric acid) and 151.65 (dilute sulfuric acidsteam pretreatment) and the corresponding value of pro- 
A

Contour plot of cellulose [\%] vs time [h], substrate conc. [\%]

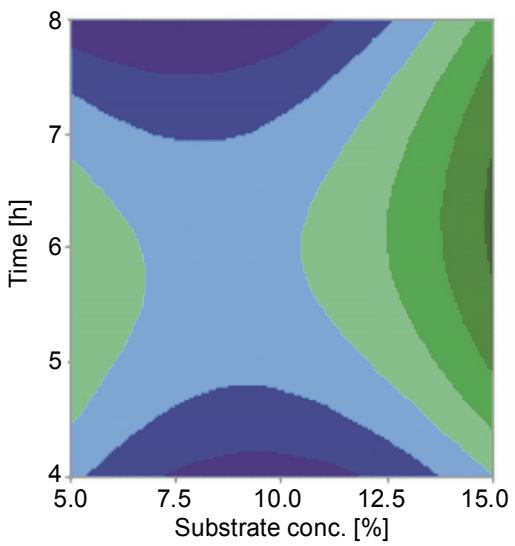

Contour plot of cellulose [\%] vs time [h], $\mathrm{H}_{2} \mathrm{SO}_{4}$ conc. [\%]
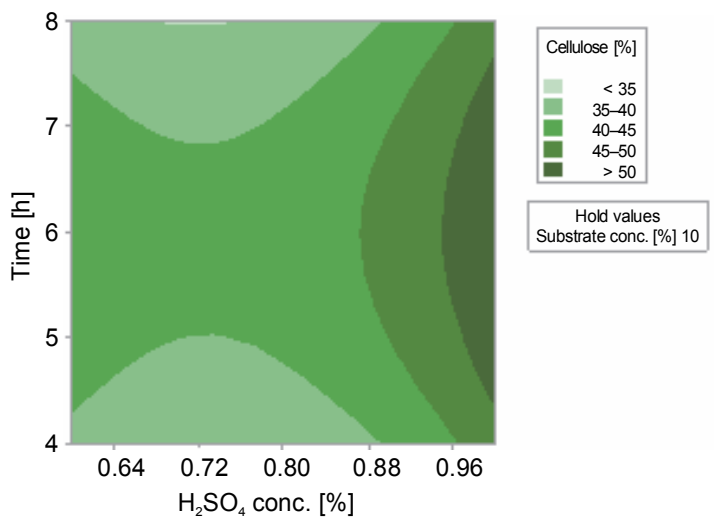

Substrate conc. [\%] 10

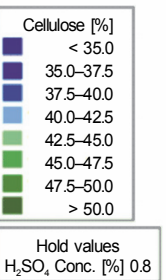

$\mathrm{H}_{2} \mathrm{SO}_{4}$ Conc. $[\%] 0.8$

(1)
B

Contour plot of cellulose [\%] vs time [h], substrate conc. [\%]
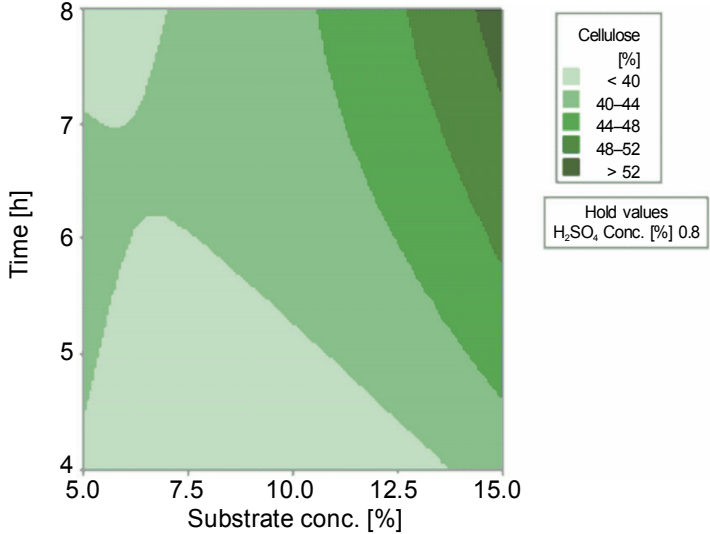

Contour plot of cellulose [\%] vs time [h], $\mathrm{H}_{2} \mathrm{SO}_{4}$ conc. [\%]

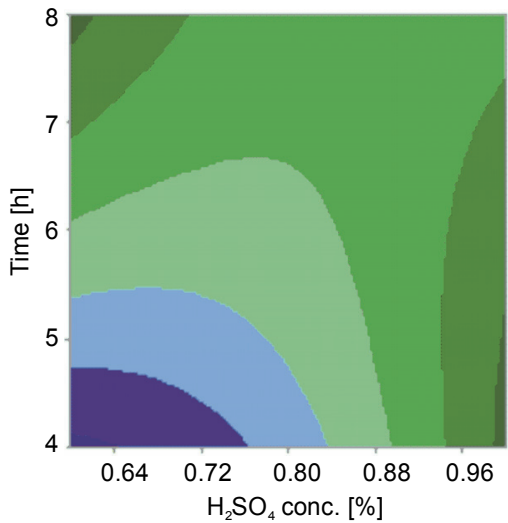

Contour plot of cellulose [\%] vs substrate conc. [\%], $\mathrm{H}_{2} \mathrm{SO}_{4}$ conc. [\%] Contour plot of cellulose [\%] vs substrate conc. [\%], $\mathrm{H}_{2} \mathrm{SO}_{4}$ conc. [\%]
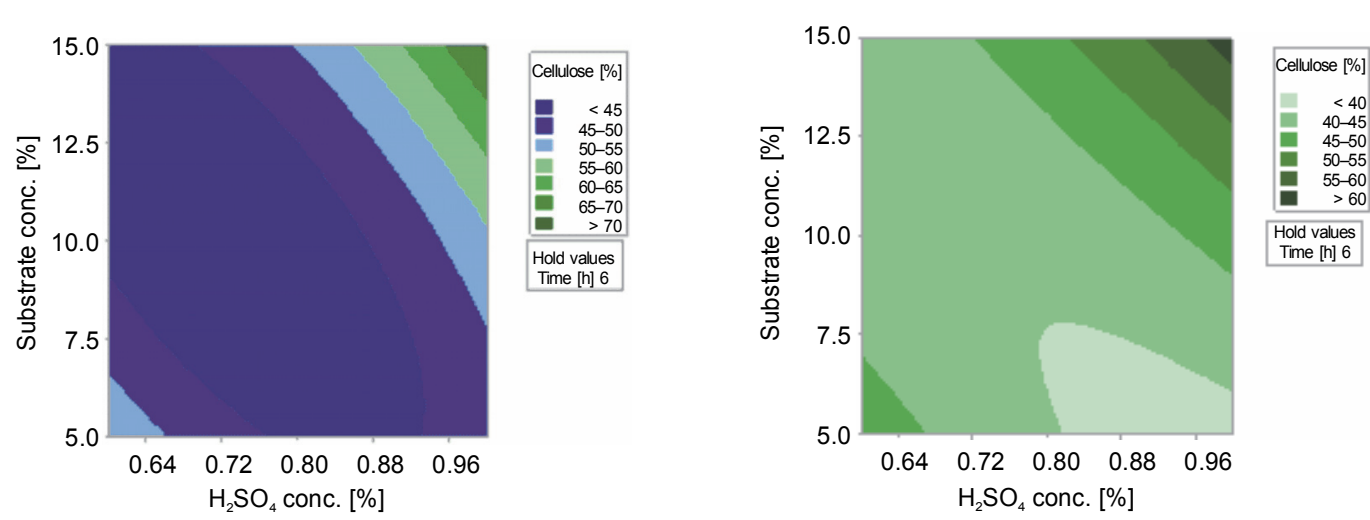

Hold values
Time $[\mathrm{h}] 6$

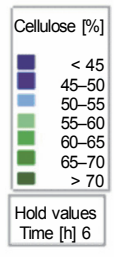

Fig. 2. Contour plots showing cellulose contents in A) acid and B) acid-steam treated peanut shells; various colors indicated the different range of cellulose content at different variables 


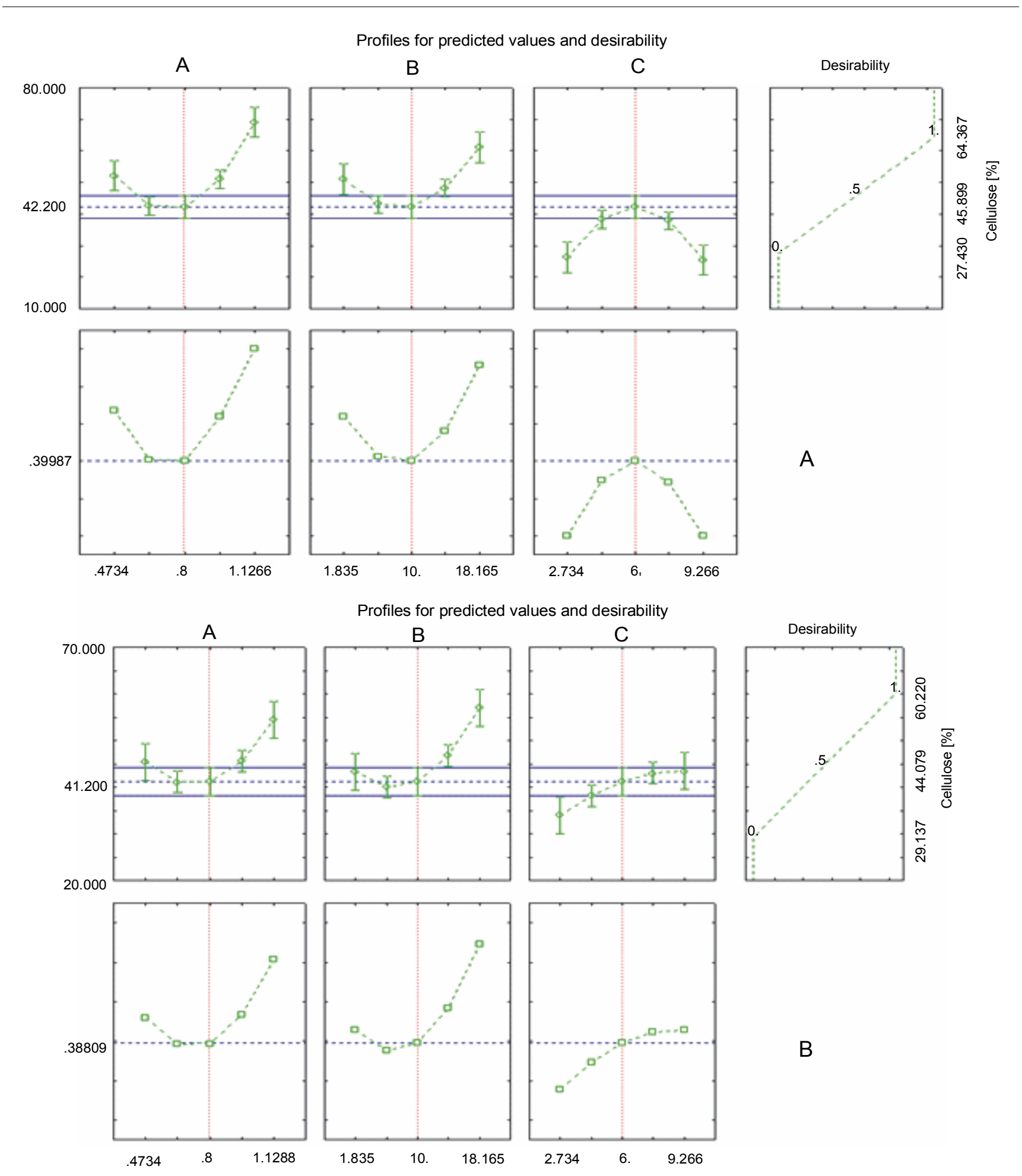

Fig. 3. Desirability chart of percentage cellulose content for A) dilute sulfuric acid pretreatment and B) dilute sulfuric acid-steam pretreatment of peanut shells 


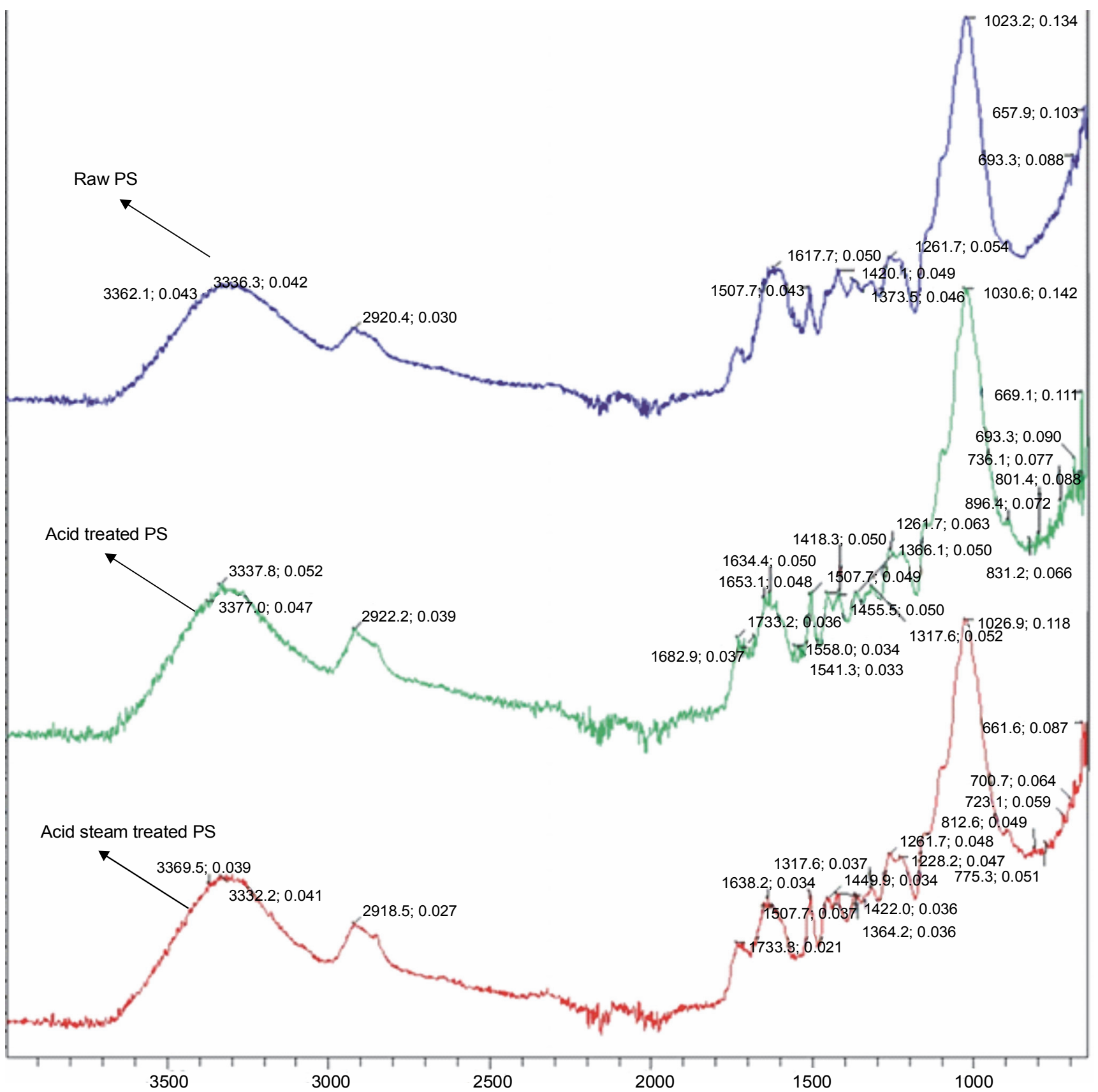

Fig 4. FTIR spectra of raw, acid pretreated, and acid-steam pretreated PS samples optimized through response surface methodology

bability $P>F<0.001$ show that the model was significant; moreover, the probability values of 0.00 and 0.00 $(P<0.05)$ showed the significance of the models. The higher $R^{2}$ value in this model was 0.9963 and 0.9965 , and its corresponding values of adjusted $R^{2}$ was 0.9898 and 0.9902 , which indicated the accuracy of the proposed model (Fig. 1). The model also successfully explains variations up to 99.63 and $99.65 \%$ in acid and acidsteam pretreatment conditions, respectively. These re- sults agree with those obtained by Bhatt and Shilpa (2014) who reported that dilute acid hydrolysis (hydrochloric acid) was the most effective out of all the chemicals that were tested.

Figure 2 shows the contour plots depicting the effect of different variables on cellulose yield. These plots clearly show that, during the pretreatment process, each factor had a significant impact on cellulose yield. In each plot, a different color area represents the range of ce- 
llulose percentage at different concentrations. Figure 3 shows the desirability chart for the percentage of cellulose yield during pretreatment. It revealed that cellulose yield could be achieved at pretreatment conditions of $0.8 \%$ sulfuric acid concentration, $10 \%$ substrate loading and a residence time of $6 \mathrm{~h}$ with a cellulose percentage of $61.93 \%$; these values were later validated by repetitive experiments.

The change in the cellulose structure of untreated, sulfuric acid pretreated, and sulfuric acid-steam pretreated samples was analyzed using FTIR spectroscopy. A significant difference between the raw and pretreated samples was observed, as shown in Figure 4. The absorption band at 900 and $1100 \mathrm{~cm}^{-1}$ was primarily observed because of the $\mathrm{C}-\mathrm{O}-\mathrm{C}$ stretching caused by the $\beta-1,4$-glycosidic linkage (Sindhu et al., 2011). Similarly, the structural changes in cellulose and hemicelluloses were observed by bands at 1000 and $1200 \mathrm{~cm}^{-1}$. C-H peaks were observed at 1281 and $1373 \mathrm{~cm}^{-1}$ (Binod et al., 2012). Moreover, the symmetric bending of $\mathrm{CH}_{2}$ was observed as peaks at 1316 and $1431 \mathrm{~cm}^{-1}$ (Cao and Tan, 2004). The peak at $2850 \mathrm{~cm}^{-1}$ was a unique feature of cellulose, which appeared because of $-\mathrm{CH}_{2}$ stretching (Sun and Cheng, 2008). Similarly, the peak at $3250 \mathrm{~cm}^{-1}$ corresponded to the stretching of the $\mathrm{H}$-bonded $\mathrm{OH}$ group (Sindhu et al., 2011).

The difference in the FTIR spectrum between the raw and pretreated samples was because of differences in various peaks. The increase in cellulose contents was visible by the increase in absorption peaks at $1000 \mathrm{~cm}^{-1}$ and $1100 \mathrm{~cm}^{-1}$ (Sun and Cheng, 2008). The increased absorption in the region at $3300 \mathrm{~cm}^{-1}$ was because of $\mathrm{O}-\mathrm{H}$ stretching, while the increased absorption at $2900 \mathrm{~cm}^{-1}$ was because of $-\mathrm{CH}_{2}$ stretching. These two bands were characteristic features of cellulose (Binod et al., 2012). The -OH stretching of hydrogen bonds was visible in the region between 3200 and $3400 \mathrm{~cm}^{-1}$ (Hsu et al., 2010). In this study, the FTIR spectra confirmed the bond stretching between the untreated and pretreated samples, indicating the effectiveness of the pretreatment process, which was optimized using RSM.

\section{Conclusions}

The results confirm that optimized pretreatment conditions of $1 \%$ dilute sulfuric acid, $15 \%$ substrate loading, and $6 \mathrm{~h}$ of residence time yielded the maximum cellulose content of $71.16 \%$ in peanut shells. Thus, this process could potentially be used for further saccharification process required for the production of fermentable sugars that are used in valuable products, particularly ethanol.

\section{References}

Alvira P., Tomas-Pejo E., Ballesteros M., Negro M.J. (2010) Pretreatment technologies for an efficient bioethanol production process based on enzymatic hydrolysis: a review. Bioresour. Technol. 101: 4851-4861.

Arshad F., Irfan M., Shakir H.A., Tabbsum F., Qazi J.I. (2017) Optimization of dilute sulphuric acid pretreatment of peanut shells through Box-Bhenken design for cellulase production by Bacillus subtilis K-18. Punjab Univ. J. Zool. 32(1): 81-90.

Bhatt S.M., Shilpa (2014) Bioethanol production from economical agro waste (Groundnut Shell) in SSF mode. Res. J. Pharm. Biol. Chem. Sci. 5(6): 1210-1215.

Binder J.B., Raines R.T. ( 2009). Simple chemical transformation of lignocellulosic biomass into furans for fuels and chemicals. J. Amer. Chem. Soc. 131: 1979-1985.

Binod P., Satyanagalakshmi K., Sindhu R., Janu K.U., Sukumaran R.K., Pandey A. (2012) Short duration microwave assisted pretreatment chances the enzymatic saccharification and fermentable sugar yield from sugarcane bagasse. Renew. Energy 37(1): 109-116.

Cao Y., Tan H. (2004) Structural characterization of cellulose with enzymatic treatment. J. Mol. Struct. 705(1-3): 189-193.

Demirbas F., Bozbas K., Balat M. (2004) Carbon dioxide emission trends and environmental problems in Turkey. Energy Expl. Exploit. 22: 355-365.

Demirbas A. (2006) Hazardous emissions, global climate change and environmental precautions. Energy Sources B 1: 75-84.

Gopal K., Ranjhan S.K. (1980) Laboratory manual for nutritional research. Roland Press (India) Private Ltd. New Dehli, India. Technology 97: 583-591.

Gajula C., Chandel A.K., Konakalla R., Rudravaram R., Pogaku R., Mangamoori L.N. (2011). Fermentation of groundnut shell enzymatic hydrolysate for fuel ethanol production by free and sorghum stalks immobilized cells of Pichia stipitis NCIM 3498. Int. J. Chem. Reactor Engin. 9(1): 1542-6580.

Hsu T.A., Ladisch M.R., Tsao G.T. (1980) Alcohol from celIulose. J. Chem. Biotechnol. 10(5): 315-319.

Hsu T.C., Guo G.L., Chen W.H., Hwang W.S. (2010) Effect of acid pretreatment of rice straw on structural properties and enzymatic hydrolysis. Bioresource Technol. 101: 4907-4913.

Jabasingh S.A., Nachiyar C.V. (2011) Utilization of pretreated bagasse for the sustainable bioproduction of cellulase by Aspergillus nidulans MTCC344 Using response surface methodology. Ind. Crops Prod. 34: 1564-1571. 
Kiran B.M., Srikantaswamy S., Pallavi H.V., Manoj V,. Tasneem T. (2013) A study on utilization of groundnut shell as biosorbant for heavy metals removal. J. Env. Sci. Comp. Sci. Engin. Technol. 2(1): 173-186.

Ruangmee A., Sanwichien C. (2013) Statistical optimization for alkali pretreatment conditions of narrow-leaf cattail by response surface methodology. Songklarin J. Sci. Technol. 35(4): 443-450.

Rothman H., Greenshields R., Calle F.R. (1983) The alcohol economy: fuel ethanol and the Brazilian experience. London: Francis Printer.

Saha B.C., Hayashi K. (2004) Lignocellulose biodegradation and applications in biotechnology. [in:] Lignocellulose biodegradation. American Chemical Society: Washington (DC): $2-34$.

Satyanagalakshmi K., Sindhu R., Binod P., Pandey A. (2011) Bioethanol production from acid pretreated water hyacinth by separate hydrolysis and fermentation. J. Sci. Ind. Res. 70(2): 156-161.
Sun Y., Cheng J. (2011) Hydrolysis of lignocellulosic materials for ethanol production. Department of Biological and Agricultural Engineering, North Carolina State University, Raleigh: 27695-27725.

Vancov T., Alston A., Brown T., McIntosh (2012) Use of ionic liquids in converting lignocellulosic material to biofuels. Renew Energy 45: 1-6.

Van Dyk J.S., Plestschke B.I. (2012) A review of lignocellulosic bioconversion using enzymatic hydrolysis and synergistic cooperation between enzyme-Factors affecting enzymes, conversion and synergy. Biotechnol. Adv. 30(6): 1458-1480.

Yat S.C., Berger A., Shonnard D.R. (2008) Kinetic characterization of dilute surface acid hydrolysis of timber varieties and switch grass. Bioresource Technol. 99: 3855-3863. 